\title{
CONTRIBUTION OF ADIPOQ GENETIC POLYMORPHISM \\ TO THE FORMATION AND COURSE OF COMORBIDITY OF NON-ALCOHOLIC FATTY LIVER DISEASE AND RENOPARENCHYMAL ARTERIAL HYPERTENSION
}

\author{
Babak Oleg, Prosolenko Kostyantyn, Panchenko Galina, \\ Shalimova Anna, Lapshina Kateryna \\ Kharkiv National Medical University, Ukraine \\ https://doi.org/10.35339/ic.8.2.100-105
}

\begin{abstract}
Background. Nowadays nonalcoholic fatty liver disease (NAFLD) is considered to be a multisystem disease that is primarily associated with components of the metabolic syndrome and is associated with cardiovascular and renal impairment. The comorbidity of NAFLD with renoparenchymal arterial hypertension (RPAH) has not been sufficiently studied. The purpose of the study was to investigate the influence of G276T genetic polymorphism of ADIPOQ on the severity of metabolic disorders, inflammation, liver, artery and kidney damage in the comorbidity of NAFLD and RPAH. Materials and methods. The study included 87 patients with comorbidity of NAFLD and RPAH, grade 2 . The mean age of patients was $50.78 \pm 9.35$ years. The vast majority of patients were overweight or obese. Moreover, the study involved investigation of 2 groups of comparison with the isolated course of NAFLD (60 patients) and RPAH (30 patients). The control group was composed of 20 healthy volunteers. Parameters of carbohydrate and lipid metabolism, liver and kidney's function, adiponectin, fetuin-A, cytokeratin-18, pro-inflammatory cytokines levels were investigated. For diagnostic of non-alcoholic steatosis and indication parameters of arteries, an ultrasound method was used. T allele was detected in $62(35.6 \%)$ patients of the main group, which was significantly $(\mathrm{p}<0,05)$ different from the control group $(22.5 \%)$. In the presence of patients with comorbidity NAFLD and RPAH G/T and T/T genotypes, carbohydrate metabolism disorders are more pronounced than in the G/G genotype. Thus, index HOMA in this group was $4.52 \pm 0.87$, which was significantly higher than patients with $\mathrm{G} / \mathrm{G}$ genotype $-3.77 \pm 0.53(\mathrm{p}<0.01)$. The G276T polymorphism of the ADIPOQ is not associated with markers of liver and kidney damage in patients with NAFLD + RPAH. The presence of G/T and T/T genotypes in patients with comorbidity of NAFLD and RPAH is associated with an increase in interleukin-6 and fetuin-A compared to the G/G genotype. Patients with comorbidity of NAFLD + RPAH and with the T allele of the polymorphic marker G276T of the ADIPOQ gene are more likely to have impaired endothelium-dependent vasodilation, indicating more significant vascular reactivity disorders $-7.72 \pm 1.25 \%$ for the genotype $\mathrm{G} / \mathrm{G}$, and $7.00 \pm 1.10 \%$ for the genotype $\mathrm{G} / \mathrm{T}(\mathrm{p}<0,01)$. Conclusions. The presence of the T allele of the polymorphic marker G276T of the ADIPOQ is associated with the development of comorbidity of NAFLD and RPAH. Keywords: nonalcoholic fatty liver disease, renoparenchymal arterial hypertension, adiponectin gene polymorphism, metabolic disorders.
\end{abstract}

\section{Introduction}

Nowadays nonalcoholic fatty liver disease (NAFLD) is considered to be a multisystem disease that is primarily associated with components of

\footnotetext{
Corresponding Author:

Kostyantyn Prosolenko MD, PhD,

Department of internal medicine 1,

Kharkiv National Medical University, Ukraine.

E-mail:prosolenko2005@ukr.net
}

the metabolic syndrome (MS) and is associated with cardiovascular and renal impairment $[2,18]$. Meanwhile, many questions about the mechanisms of chronic kidney disease (CKD) in patients with NAFLD remain unclear, especially in combination with hypertension $(\mathrm{AH})[1,19]$. The comorbidity of NAFLD with renoparenchymal arterial hypertension (RPAH) has not been sufficiently studied. 
It is well known that genetic factors play an important role in the development and course of such common diseases as NAFLD and AH $[8,11,12]$. Hypoadiponectinemia is a proven pathogenetic factor in the development of both NAFLD and AH $[4,5]$. Adiponectin levels have been shown to have individual genetic differences [21].

The production and activity of adiponectin depends on the structure of the adiponectin gene (ADIPOQ), located on chromosome 3 at locus $3 q 27$. The polymorphic marker G276T of the ADIPOQ gene is considered to be the most clinically significant in the development of insulin resistance (IR), obesity, and type 2 diabetes [9, 20].

\section{Purpose, subjects and methods:}

2.1. The purpose of the study was to investigate the influence of G276T genetic polymorphism of ADIPOQ on the severity of metabolic disorders, inflammation, liver, artery and kidney damage in the comorbidity of NAFLD and RPAH.

\subsection{Subjects \& Methods}

Patients were examined at the Department of Gastroenterology and Therapy of the Government Institution "L.T.Malaya Therapy National Institute of the National Academy of Medical Sciences of Ukraine". Clinical and biochemical studies were conducted in the clinical diagnostic laboratory of the Government Institution "L.T.Malaya Therapy National Institute of the National Academy of Medical Sciences of Ukraine" and laboratory "Alpha Labservice".

The study included 87 patients with comorbidity of NAFLD and RPAH, grade 2. All patients had CKD no more than stage IIIA as a result of chronic pyelonephritis. The mean age of patients was $50.78 \pm 9.35$ years. Among them were 51.7 $\%$ men and $48.3 \%$ women. The distribution of patients by sex was uniform. The vast majority of patients were overweight or obese.

The study did not include patients with type 1 and 2 diabetes, other diffuse and focal liver diseases (viral hepatitis, alcoholic liver disease, liver cirrhosis, etc.), the presence of other comorbidities in patients with NAFLD: coronary artery disease (CAD), rheumatic heart defects, oncological diseases, systemic connective tissue diseases, CHF II B - III stages, AH I and III stages, echo-negativity, patients' refusal to study, pregnancy and lactation.

Moreover, the study involved investigation of 2 groups of comparison with the isolated course of NAFLD (60 patients) and RPAH (30 patients). The control group consisted of 20 healthy individuals of the same age category, male and female.
The research was performed in compliance with the basic provisions of the "Rules of ethical principles of scientific medical research with human participation", approved by the Declaration of Helsinki (1964-2013), ICH GCP (1996), EEC Directive No. 609 (dated 24.11.1986), orders of the Ministry of Health of Ukraine No. 690 dated 23.09.2009, No. 944 dated 14.12.2009, No. 616 dated 03.08.2012. Each patient signed an informed consent to participate in the study.

Clinical examination of patients included assessment of the parameters of objective examination: in particular, anthropometric data and blood pressure (BP) according to standard methods.

Non-alcoholic steatosis and indication parameters of arteries were evaluated by an ultrasound method (ultrasound diagnostic system "GE", USA). The degree of endothelium-dependent vasodilation (EDVD) was determined in a sample with reactive hyperemia [3].

Concentration of total cholesterol (TC) and its fractions: high-density lipoprotein cholesterol (HDL), low-density lipoprotein cholesterol (LDL) and triglycerides (TG), aminotransferases (AST, ALT), gamma-glutamiltranpeptidase (GGT) were determined by standard generally accepted methods. The HOMA index was also determined. The glomerular filtration rate (GFR) was calculated by the formula CKD-EPI.

The AviBion Human Adiponectin (Acrp30) Elisa Kit test system (Ani Biotech Oy Orgenium Laboratories Busines Unit, Finland) was used to determine adiponectin levels. Fetuin-A values (fet-A) were determined in serum by ELISA (Biovendor, Czech Republic). The levels of cytokeratin-18 (CK-18), which is a marker of inflammation and apoptosis of the liver [7], in the blood plasma were determined by ELISA using a set of CK18 (M65) Human ELISA Kit manufactured by Biotech (China). The concentrations of proinflammatory cytokines (tumor necrosis factor- $\alpha$ (TNF- $\alpha$ ) and interleukin-6 (IL-6)) in the blood serum were evaluated using Vector-Best kits.

Based on the data of the polymer chain reaction with direct (5'-GGCCTCTTTCATCACAGACC-3') and reverse (5'-AGATGCAGCAAAGCCAAAGT-3') primers, the genetic polymorphism of ADIPOQ was determined. The amplification products were incubated with BsmI restriction enzyme in buffer. The hydrolysis products were isolated in a polyacrylamide gel and visualized under ultraviolet light. Three ADIPOQ genotypes (G/ $\mathrm{G}, \mathrm{G} / \mathrm{T}$ and $\mathrm{T} / \mathrm{T}$ ) were identified by $\mathrm{G} 276 \mathrm{~T}$ polymorphism. 
Statistical processing of the results was performed using computer programs Microsoft Excel and STATISTICA using standard methods of variation statistics. To assess the significance of the difference in pairwise changes, we used the $\mathrm{t}-$ Student test $(M \pm \sigma)$. The difference was considered statistically significant at $\mathrm{p}<0.05$.

\section{Results \& Discussion}

A corresponding comparative analysis of the distribution of ADIPOQ alleles and genotypes in the NAFLD + RPAH comorbidity and control groups was performed.

In patients with NAFLD + RPAH, the homozygous $\mathrm{G} / \mathrm{G}$ genotype was found in 35 (40.2\%) patients, the heterozygous G/T genotype in 42 (48.3\%), and the homozygous $\mathrm{T} / \mathrm{T}$ genotype in $10(11.5 \%)$ patients. In the comparison groups, the distribution of genotypes did not significantly differ from the comorbidity group and significantly differed from the control group (Table 1).

It was found that the $\mathrm{T}$ allele was detected in $62(35.6 \%)$ patients of the main group, which was significantly $(\mathrm{p}<0.05)$ different from the control group $(22.5 \%)$ (Table 1).

Then we proceeded to the analysis of anamnestic, clinical-laboratory, anthropometric and instrumental-functional features in the NAFLD + RPAH group.

A difference between groups of patients with $\mathrm{G} / \mathrm{G}$ and $\mathrm{T} / \mathrm{T}$ genotypes in terms of body mass index (BMI) was found. Patients with $\mathrm{G} / \mathrm{G}$ and $\mathrm{G} / \mathrm{T}$ genotypes of the ADIPOQ had significantly lower BMI $(\mathrm{p}<0.01)$, respectively, than patients with $\mathrm{T} / \mathrm{T}$ genotype $(\mathrm{p}<0.01)$.

The influence of the polymorphism of the studied gene on blood pressure was not detected $(\mathrm{p}>0,05)$ (Table 2). In the analysis of Doppler parameters there were significant differences of EDVD - 7.72 $\pm 1.25 \%$ for the genotype $\mathrm{G} / \mathrm{G}$, and $7.00 \pm 1.10 \%$ for the genotype $G / T(p<0,01)$. The thickness of the intima-media complex of the common carotid artery (TIM CCA) was greater with G/T genotype compared with $\mathrm{T} / \mathrm{T}$ genotype $(\mathrm{p}<0.05)$.
Significant differences in the analysis of carbohydrate metabolism between patients were found. Carbohydrate metabolism was worst in patients with the $\mathrm{T} / \mathrm{T}$ genotype compared to patients with the G/G genotype. Thus, HOMA-IR in this group was significantly higher than patients with $\mathrm{G} / \mathrm{G}$ genotype $(\mathrm{p}<0.01)$.

When evaluating the lipid profile, we did not find the dependence of lipid parameters on ADIPOQ genotypes. There was also no association between ADIPOQ genotypes and renal function $(p>0.05)$. GFR in the group $\mathrm{G} / \mathrm{G}$ genotype was $71.46 \pm 12.19 \mathrm{ml} / \mathrm{min} / 1.73 \mathrm{~m}^{2}$ and did not differ from patients with $\mathrm{G} / \mathrm{T}$ and $\mathrm{T} / \mathrm{T}$ genotypes $-68.76 \pm 12.29$ and $65.67 \pm 13,68 \mathrm{ml} /$ $\mathrm{min} / 1.73 \mathrm{~m}^{2}$, respectively $(\mathrm{p}>0.05)$.

At the same time, the G276T polymorphism of the ADIPOQ significantly affected the levels of fet-A and adiponectin. Thus, in patients with $\mathrm{G} / \mathrm{G}$ genotype adiponectin was more than in the $\mathrm{G} / \mathrm{T}$ genotype $(p<0.01)$, and at $\mathrm{T} / \mathrm{T}$ genotype $-(\mathrm{p}<0.01)$.

Also, the pro-inflammatory cytokine IL-6 was significantly higher in the group $\mathrm{G} / \mathrm{T}$ genotype compared with the group $\mathrm{G} / \mathrm{G}$ g/enotype (p $<0.05$ )

Given the known negative effect of the T allele, the groups of $\mathrm{G} / \mathrm{T}$ and $\mathrm{T} / \mathrm{T}$ genotypes were combined and all indicators were evaluated in comparison with the $\mathrm{G} / \mathrm{G}$ genotype group (Table 3).

Significant differences were found in BMI, insulin, HOMA, IL-6, adiponectin, EDVD and fet-A. Thus, fet-A in the group of genotype $\mathrm{G} / \mathrm{G}$ was $301.47 \pm 25.14 \mathrm{ng} / \mathrm{ml}$ against $315.22 \pm 17.29 \mathrm{ng} / \mathrm{ml}$ in the group of genotype $\mathrm{G} / \mathrm{T}+\mathrm{T} / \mathrm{T}(\mathrm{p}<0,01)$. Worse indicators were in carriers of the $\mathrm{T}$ allele, which indicates the influence of this parameter on anthropometric, proinflammatory, vascular and metabolic factors in patients with comorbidity of NAFLD and RPAH.

There were no significant differences in other indicators $(\mathrm{p}>0.05)$.

Importantly, there is an association between an increase in the $\mathrm{T}$ allele and an increase in fetuin

Table 1

Distribution of ADIPOQ alleles and genotypes in groups of NAFLD + RPAH comorbidity, comparison and control

\begin{tabular}{|l|c|c|c|c|}
\hline \multirow{2}{*}{ Parameters } & NAFLD + RPAH group & NAFLD group & RPAH group & Control group \\
\cline { 2 - 5 } & $\mathrm{n}=87$ & $\mathrm{n}=60$ & $\mathrm{n}=30$ & $\mathrm{n}=20$ \\
\hline $\mathrm{G} / \mathrm{G}$ & $35(40.2 \%)^{*}$ & $18(30 \%)^{*}$ & $12(40 \%)^{*}$ & $13(65 \%)$ \\
\hline $\mathrm{G} / \mathrm{T}$ & $42(48.3 \%)^{*}$ & $34(56.7 \%)^{*}$ & $14(46.7 \%)^{*}$ & $5(25 \%)$ \\
\hline $\mathrm{T} / \mathrm{T}$ & $10(11.5 \%)$ & $8(13.3 \%)$ & $4(13.3 \%)$ & $2(10 \%)$ \\
\hline $\mathrm{G}$ allele & $112(64.4 \%)^{*}$ & $70(58.3 \%)^{*}$ & $38(63.3 \%)^{*}$ & $31(77.5 \%)$ \\
\hline T allele & $62(35.6 \%)^{*}$ & $50(41.7 \%)^{*}$ & $22(36.7 \%)^{*}$ & $9(22.5 \%)$ \\
\hline
\end{tabular}


Table 2

Parameters in patients with comorbidity NAFLD + RPAH depending on ADIPOQ genotypes

\begin{tabular}{|c|c|c|c|}
\hline Parameters & Genotype G/G, n=35 & Genotype $\mathrm{G} / \mathrm{T}, \mathrm{n}=42$ & Genotype $T / T, n=10$ \\
\hline $\mathrm{BMI}, \mathrm{kg} / \mathrm{m}^{2}$ & $31.74 \pm 3.92$ & $31.59 \pm 3.53$ & $34.37 \pm 2.50^{* \star \wedge}$ \\
\hline SBP, $\mathrm{mm} \mathrm{Hg}$ & $171.74 \pm 5.07$ & $172.57 \pm 4.41$ & $172.90 \pm 5.38$ \\
\hline $\mathrm{DBP}, \mathrm{mm} \mathrm{Hg}$ & $101.83 \pm 3.61$ & $102.81 \pm 3.60$ & $101.80 \pm 3.94$ \\
\hline Average $\mathrm{BP}, \mathrm{mm} \mathrm{Hg}$ & $131.19 \pm 3.64$ & $132.11 \pm 3.44$ & $131.66 \pm 4.32$ \\
\hline TIM CCA, sm & $0.88 \pm 0.12$ & $0.93 \pm 0.13$ & $0.84 \pm 0.11^{\wedge}$ \\
\hline EDVD,\% & $7.72 \pm 1.25$ & $7.00 \pm 1.10^{*}$ & $7.30 \pm 1.39$ \\
\hline $\mathrm{AST}, \mathrm{U} / \mathrm{I}$ & $45.97 \pm 28.63$ & $57.00 \pm 36.70$ & $48.40 \pm 14.84$ \\
\hline $\mathrm{ALT}, \mathrm{U} / \mathrm{I}$ & $51.91 \pm 32.00$ & $69.81 \pm 54.83^{*}$ & $56.20 \pm 12.84$ \\
\hline GGT, U / I & $64.53 \pm 26.59$ & $73.30 \pm 39.63$ & $58.40 \pm 24.77$ \\
\hline TC, $\mathrm{mmol} / \mathrm{I}$ & $5.93 \pm 0.80$ & $5,97 \pm 0.94$ & $6.14 \pm 0.64$ \\
\hline TG, $\mathrm{mmol} / \mathrm{I}$ & $2.24 \pm 0.89$ & $2.18 \pm 0.97$ & $2.48 \pm 1.14$ \\
\hline $\mathrm{HDL}, \mathrm{mmol} / \mathrm{l}$ & $1.25 \pm 0.47$ & $1.25 \pm 0.34$ & $1.16 \pm 0.25$ \\
\hline LDL, $\mathrm{mmol} / \mathrm{I}$ & $3.88 \pm 0.84$ & $4.04 \pm 0.96$ & $4.13 \pm 0.56$ \\
\hline Blood glucose, $\mathrm{mmol} / \mathrm{l}$ & $5.63 \pm 0,54$ & $5.64 \pm 0.52$ & $5.78 \pm 0.57$ \\
\hline HOMA-IR & $3.77 \pm 0,53$ & $4.20 \pm 0.76$ & $4.52 \pm 0.87^{* *}$ \\
\hline Creatinine, $\mu \mathrm{mol} / \mathrm{I}$ & $97.37 \pm 9.60$ & $100.74 \pm 12.28$ & $93.00 \pm 15.30$ \\
\hline GFR, $\mathrm{ml} / \mathrm{min} / 1.73 \mathrm{~m}^{2}$ & $71.46 \pm 12.19$ & $68.76 \pm 12.29$ & $65.67 \pm 13.68$ \\
\hline $\mathrm{IL}-6, \mathrm{pg} / \mathrm{ml}$ & $20.32 \pm 3.59$ & $21.75 \pm 2.30^{*}$ & $21.58 \pm 2.93$ \\
\hline TNF- $\alpha, p g / m l$ & $11.16 \pm 2.28$ & $11.86 \pm 1.74$ & $10.46 \pm 1.93$ \\
\hline Adiponectin, $\mathrm{ng} / \mathrm{ml}$ & $6.36 \pm 0.52$ & $6.10 \pm 0.45^{*}$ & $6.13 \pm 0.52^{* *}$ \\
\hline Fet-A, ng / ml & $301.47 \pm 25.14$ & $314.16 \pm 17.90^{*}$ & $319.64 \pm 14.38^{\star *}$ \\
\hline CK-18, U/I & $309.59 \pm 51.82$ & $321.31 \pm 52.25$ & $312.80 \pm 62.31$ \\
\hline
\end{tabular}

Note: ${ }^{*}$ - statistically significant differences between $\mathrm{G} / \mathrm{G}$ and $\mathrm{G} / \mathrm{T}$ genotypes; ${ }^{* *}-$ statistically significant differences between $\mathrm{G} / \mathrm{G}$ and $\mathrm{T} / \mathrm{T}$ genotypes; ${ }^{\wedge}$ - statistically significant differences between $\mathrm{G} / \mathrm{T}$ and $\mathrm{T} / \mathrm{T}$

Table 3

Comparative evaluation of metabolic parameters of patients with comorbidity of NAFLD and $R P A H$ in $G / G$ and $G / T+T / T$ genotypes $A D I P O Q$

\begin{tabular}{|c|c|c|}
\hline Parameters & Genotype G/G, n=35 & Genotype G/T+T/T, n=52 \\
\hline $\mathrm{BMI}, \mathrm{kg} / \mathrm{m} 2$ & $31.74 \pm 3.92$ & $33.86 \pm 3.52^{*}$ \\
\hline SBP, $\mathrm{mm} \mathrm{Hg}$ & $171.74 \pm 5.07$ & $172.6 \pm 34.56$ \\
\hline $\mathrm{DBP}, \mathrm{mm} \mathrm{Hg}$ & $101.83 \pm 3.61$ & $102.62 \pm 3.65$ \\
\hline Average $\mathrm{BP}, \mathrm{mm} \mathrm{Hg}$ & $131.19 \pm 3.64$ & $132.02 \pm 3.59$ \\
\hline TIM CCA, sm & $0.88 \pm 0.12$ & $0.91 \pm 0.13$ \\
\hline EDVD,\% & $7.72 \pm 1.25$ & $7.06 \pm 1.15^{*}$ \\
\hline AST, U /I & $45.97 \pm 28.63$ & $55.35 \pm 33.66$ \\
\hline $\mathrm{ALT}, \mathrm{U} / \mathrm{I}$ & $51.91 \pm 32.00$ & $67.19 \pm 49.75$ \\
\hline GGTP, U /I & $64.53 \pm 26.59$ & $70.43 \pm 37.50$ \\
\hline $\mathrm{TC}, \mathrm{mmol} / \mathrm{I}$ & $5.93 \pm 0.80$ & $6.00 \pm 0.88$ \\
\hline TG, $\mathrm{mmol} / \mathrm{l}$ & $2.24 \pm 0.89$ & $2.24 \pm 1.00$ \\
\hline $\mathrm{HDL}, \mathrm{mmol} / \mathrm{I}$ & $1.25 \pm 0.47$ & $1.23 \pm 0.32$ \\
\hline LDL, $\mathrm{mmol} / \mathrm{I}$ & $3.88 \pm 0.84$ & $4.06 \pm 0.90$ \\
\hline Blood glucose, $\mathrm{mmol} / \mathrm{l}$ & $5.63 \pm 0.54$ & $5.67 \pm 0.53$ \\
\hline HOMA-IR & $3.77 \pm 0.53$ & $4.26 \pm 0.79^{*}$ \\
\hline Creatinine, $\mu \mathrm{mol} / \mathrm{l}$ & $97.37 \pm 9.60$ & $99.25 \pm 13.11$ \\
\hline GFR, $\mathrm{ml} / \mathrm{min} / 1.73 \mathrm{~m}^{2}$ & $71.46 \pm 12.19$ & $68.17 \pm 12.49$ \\
\hline $\mathrm{IL}-6, \mathrm{pg} / \mathrm{ml}$ & $20.32 \pm 3.59$ & $21.72 \pm 2.40^{*}$ \\
\hline TNF- $\alpha, p g / m l$ & $11.16 \pm 2.28$ & $11.59 \pm 1.84$ \\
\hline Adiponectin, $\mathrm{ng} / \mathrm{ml}$ & $6.36 \pm 0.52$ & $6.12 \pm 0.46^{*}$ \\
\hline Fet-A, ng / ml & $301.47 \pm 25.14$ & $315.22 \pm 17.29^{*}$ \\
\hline CK-18, U/I & $309.59 \pm 51.82$ & $319.67 \pm 53.77$ \\
\hline
\end{tabular}

Note: ${ }^{*}-$ statistically significant differences between $\mathrm{G} / \mathrm{G}$ and $\mathrm{G} / \mathrm{T}+\mathrm{T} / \mathrm{T}$ genotypes. 
levels, which, according to researchers, may affect the course of NAFLD, hypertension and $\mathrm{CKD}$. Interesting are the data concerning the correlations of levels of fet-A and adiponectin, which also has an important influence on the pathogenesis of NAFLD. It is a key regulator of end-organ damage in obesity, CKD, and NAFLD $[6,13]$. The genes for fet-A and adiponectin are located in 3q27 in the human genome. They can work in concert to regulate IR. Indicators of both of these proteins are closely related to the components of MS, but in opposite directions. Higher fet-A and low adiponectin may contribute to IR and the development of type 2 diabetes [16, 23].

Analyzing the obtained results, we can state the presence of the influence of the G276T polymorphism of the ADIPOQ on metabolic and inflammatory parameters, as well as the condition of the arteries in patients with comorbidity of NAFLD and RPAH. The meta-analysis of Liu J et al., 2019 [10] also testifies to the influence of the G276T polymorphism of the ADIPOQ on the origin and course of NAFLD. Regarding carbohydrate metabolism disorders in NAFLD, our data are the same as those obtained in recent studies [17]. The data of our study confirm the influence of the G276T polymorphism of the ADIPOQ gene on biochemical parameters in patients with NAFLD and AH $[10,14,15]$.

\section{Conclusions}

It can be stated that the presence of the $T$ allele of the polymorphic marker G276T of the ADIPOQ is associated with the development of more pronounced metabolic and pro-inflammatory changes in patients with comorbidity of NAFLD + RPAH.

In the presence of patients with comorbidity NAFLD and RPAH G/T and T/T genotypes, carbohydrate metabolism disorders are more pronounced than in the G/G genotype.
The G276T polymorphism of the ADIPOQ is not associated with markers of liver damage in patients with NAFLD + RPAH.

The presence of $\mathrm{G} / \mathrm{T}$ and $\mathrm{T} / \mathrm{T}$ genotypes in patients with comorbidity of NAFLD and RPAH is associated with an increase in IL-6 and fet-A compared to the $\mathrm{G} / \mathrm{G}$ genotype.

Patients with comorbidity of NAFLD + RPAH and with the $\mathrm{T}$ allele of the polymorphic marker G276T of the ADIPOQ gene are more likely to have impaired EDVD, indicating more significant vascular reactivity disorders.

Thus, the role and place of G276T polymorphism of the ADIPOQ gene in patients with comorbidity of NAFLD and RPAH have been established.

\section{Limitations of the study}

The control and comparison groups included a small number of patients, while sufficient to determine statistically significant differences. For a more accurate distribution of genotypes and the effect of this on the course of diseases, it is desirable to conduct larger studies with the involvement of a larger number of patients.

\section{Declarations:}

\section{Statement of Ethics}

The authors have no ethical conflicts to disclosure.

\section{Consent for publication}

All authors give their consent to publication.

\section{Disclosure Statement}

The authors have no potential conflicts of interest to disclosure.

\section{Funding Sources}

This project was supported by Kharkiv National Medical University, Kharkiv, Ukraine.

Data Transparency

The data can be requested from the authors.

\section{References}

1. Adams LA, Anstee QM, Tilg H, Targher G. (2017) Non-alcoholic fatty liver disease and its relationship with cardiovascular disease and other extrahepatic diseases. Gut. 2017;66(6): 1138-53. doi: 10.1136/gutjnl-2017-313884

2. Byrne CD, Targher G. (2015) NAFLD: a multisystem disease. J. Hepatol. 2015;62 (1 Suppl):S4764. doi: $10.1016 /$ j.jhep.2014.12.012

3. Celermajer D, Sorensen K, Gooch V, Spiegelhalter D, Miller O, Sullivan I, et al. (1992) Noninvasive detection of endothelial dysfunction in children and adults at risk of atherosclerosis. The Lancet. 1992;340:1111-5. doi:10.1016/0140-6736(92)93147-f.

4. Hui JM, Hodge A, Farrell GC, Kench JG, Kriketos A, George J. (2004) Beyond insulin resistance in NASH: TNF-alpha or adiponectin? Hepatology. 2004;40:46-54.

5. Iminova DA, Alyavi AL, Sobirova GN (2019) Association of Gene Polymorphism Adipoq +276 (G / T) with Surrogatic Markers of the Increased Fat Content in the Liver. American Journal of Medicine and Medical Sciences. 2019; 9(12): 464-466. DOI: 10.5923/j.ajmms.20190912.03 
6. Ix JH, Sharma K. (2010) Mechanism linking obesity, chronic kidney disease and fatty liver disease: the roles of fetuin-A, adiponectin and AMPK. J Am Soc Nephrol. 2010;21(3):406-12.

7. Kanda T, Matsuoka S, Yamazaki M. (2018) Apoptosis and non-alcoholic fatty liver diseases. World J Gastroenterol. 2018;24(25): 2661-72. doi: 10.3748/wjg.v24.i25.2661

8. Kawaguchi T, Sumida Y, Umemura A, Matsuo K, Takahashi M, Takamura T, et al.; Japan Study Group of Nonalcoholic Fatty Liver Disease. (2012) Genetic polymorphisms of the human PNPLA3 gene are strongly associated with severity of non-alcoholic fatty liver disease in Japanese. PLoS One. 2012;7(6):e38322. doi: 10.1371/journal.pone.0038322

9. Lin CH, Ho CY, Liu CS. (2012) Influence of Adiponectin Gene Polymorphisms on Adiponectin Serum Level and Insulin Resistance Index in Taiwanese Metabolic Syndrome Patients. Chin J Physiol. 2012;55(6):405-411.

10. Liu J, Xing J, Wang B, Wei C, Yang R, Zhu Y, Qiu H (2019) Correlation Between Adiponectin Gene rs1501299 Polymorphism and Nonalcoholic Fatty Liver Disease Susceptibility: A Systematic Review and Meta-Analysis. Med Sci Monit. 2019; 25: 1078-1086. doi: 10.12659/MSM.912737.

11. Lowry DE, Fenwick PH, Roke K, Jeejeebhoy K, Dhaliwal R, Brauer P, et al. (2018) Variants in APOA5 and ADIPOQ Moderate Improvements in Metabolic Syndrome during a One-Year Lifestyle Intervention. Lifestyle Genom. 2018;11(2):80-9. doi: 10.1159/000494331

12. Mantovani A, Zusi C, Sani E, Colecchia A, Lippi G, Zaza GL, et al. (2019) Association between PNPLA3rs738409 polymorphism decreased kidney function in postmenopausal type 2 diabetic women with or without non-alcoholic fatty liver disease. Diabetes Metab. 2019;45:480-7.

13. Mohseni F, Moghbelinejad S, Najafipour R (2017) Major Components of Metabolic Parameters and Nutritional Intakes in Different Genotypes of Adiponectin +276 G>T Gene Polymorphism in NonDiabetes and Non-Alcoholic Iranian Fatty Liver Patients. Avicenna J Med Biotechnol. 2017; 9(3): 155161. PMCID: PMC5501145

14. Semple RK (2017) How does insulin resistance arise, and how does it cause disease? Human genetic lessons. European Journal of Endocrinology. 2017; 174: R209-R223.

15. Shalimova A, Fadieienko G, Kolesnikova O, Isayeva A, Zlatkina V, Nemtsova V, Prosolenko K, Psarova V, Kyrychenko N, Kochuieva M (2019) The role of genetic polymorphism in the formation of arterial hypertension, type 2 diabetes and their comorbidity, Current Pharmaceutical Design. 2019, 25, 218-227.

16. Sheng T, Yang K. (2008) Adiponectin and its association with insulin resistance and type 2 diabetes. J Genet Genom. 2008;35:321-326.

17. Siitonen N, Pulkkinen L, Lindstr?m J. (2011) Association of ADIPOQ gene variants with body weight, type 2 diabetes and serum adiponectin concentrations: the Finnish Diabetes Prevention Study. BMC Med Genet. 2011;10:12-15.

18. Targher G, Bertolini L, Rodella S, Lippi G, Zoppini G, Chonchol M. (2010) Relationship between kidney function and liver histology in subjects with nonalcoholic steatohepatitis. Clin J Am Soc Nephrol. 2010;5(12):2166-71. doi: 10.2215/CJN.05050610

19. Thrasher T, Abdelmalek MF. (2016) Nonalcoholic fatty liver disease. N C Med J. 2016;77 (3):216-9.

20. Wang BF, Wang Y, Ao R, Tong J, Wang BY (2016) AdipoQ T45 G and G276 T Polymorphisms and Susceptibility to Nonalcoholic Fatty Liver Disease Among Asian Populations: A Meta-Analysis and Meta-Regression. J Clin Lab Anal. 2016; 30(1): 47-57. doi: 10.1002/jcla.21814.

21. Whitehead JP, Richards AA, Hickman IJ. (2006) Adiponectin - a key adipokine in the metabolic syndrome. Diab, Obes, Metabol. 2006;8:264-280.

22. Xu Y, Xu M, Bi Y, et al. (2011) Serum fetuin-A is corretaled with metabolic syndrome in middleaged and elderly Chinese. Atherosclerosis 2011;216(1):180-6.

Received: 03-Feb-2021

Accepted: 17-Jun-2021 